Tropical Journal of Pharmaceutical Research September 2020; 19 (9): 1927-1931

ISSN: $1596-5996$ (print); 1596-9827 (electronic) (C) Pharmacotherapy Group, Faculty of Pharmacy, University of Benin, Benin City, 300001 Nigeria.

\title{
Investigation of the antidepressant effects of Shu-Gan-Jie- Yu granule and its mechanism of action
}

\author{
Li-shu Gao1, Min Wu${ }^{2 *}$, Yue Gao ${ }^{3}$, En-ping $\mathrm{Xu}^{4}$, Jian $\mathrm{Xie}^{1}$ \\ ${ }^{1}$ Department of Clinical Psychology, ${ }^{2}$ Department of Infectious Disease, ${ }^{3}$ Department of Gerontology, Affiliated Hangzhou First \\ People's Hospital, Zhejiang University School of Medicine, Hangzhou, Zhejiang 310006, ${ }^{4}$ Department of Pathology, School of \\ Medicine, Zhejiang University, Hangzhou, Zhejiang 310058, PR China
}

*For correspondence: Email: wuminhz@163.com

Sent for review: 21 February 2019

Revised accepted: 23 August 2020

\begin{abstract}
Purpose: To study the antidepressant effects of Shu-Gan-Jie-Yu granule (SJG) and its possible mechanisms in mice.

Methods: The anti-depressive effects of SJG were evaluated by three techniques, viz, forced swimming test (FST), tail suspension test (TST) and open field test (OFT). The levels of the neurotransmitters norepinephrine (NE), DA, and 5-HT in the brains of depressive mice were determined using commercially available kits. In addition, the effects of SJG on the BDNF expression in the mice brain were determined by western blot.

Results: Administration of SJG significantly reduced the duration time of immobility in the experiments of FST and TST. In addition, relative to the control mice, SJG (800 mg/kg) administration significantly affected the mobility performance $(p<0.05)$ of mice. The levels of the three neurotransmitters $(D A, N E$ and 5-HT) and BDNF in the brains of depressive mice were increased by treatment with SJG at the doses of 200,400 and $800 \mathrm{mg} / \mathrm{kg}(p<0.05)$. The results suggested that SJG exerted a significant antidepressant effect, which could be attributed to increases in the levels of neurotransmitters, and the up-regulation of BDNF expression.

Conclusion: The results suggested that SJG exerted a significant antidepressant effect, most probably via regulation of related neurotransmitters (including DA, NE, and 5-HT) and BDNF in the brain.
\end{abstract}

Keywords: Shu-Gan-Jie-Yu granule, Antidepressant, dopamine, norepinephrine, 5-hydroxytryptamine, brain-derived neurotrophic factor

\begin{abstract}
This is an Open Access article that uses a fund-ing model which does not charge readers or their institutions for access and distributed under the terms of the Creative Commons Attribution License (http://creativecommons.org/licenses/by/4.0) and the Budapest Open Access Initiative (http://www.budapestopenaccessinitiative.org/read), which permit unrestricted use, distribution, and reproduction in any medium, provided the original work is properly credited.
\end{abstract}

Tropical Journal of Pharmaceutical Research is indexed by Science Citation Index (SciSearch), Scopus, International Pharmaceutical Abstract, Chemical Abstracts, Embase, Index Copernicus, EBSCO, African Index Medicus, JournalSeek, Journal Citation Reports/Science Edition, Directory of Open Access Journals (DOAJ), African Journal Online, Bioline International, Open-J-Gate and Pharmacy Abstracts

\section{INTRODUCTION}

It's well known that depression is a very common chronic recurrent syndrome and the main reason for the increase of suicide and physical disorders [1]. Despite significant progress in the diagnosis and care of patients with depression, many patients who experience depression still have no access to satisfactory treatment. Depression is a mental disorder characterized by persistent depression and self-denial, and its pathogenesis is highly complex. Its pathogenesis is very complex. Depression is generally considered to be caused by genetic and environmental stressors, although the specific pathological mechanism remains unclear [2]. Furthermore, it 
has been reported that current medications used to treat depression have a series of side effects, such as constipation, dry mouth, and sexual dysfunction [3]. Therefore, it is urgent to find more safe and effective drugs to treat depression.

Shu-Gan-Jie-Yu granule (SJG) is the first traditional Chinese medicine approved for clinical prescription by the State Food and Drug Administration to treat depression [2]. SJG is a compound preparation purified using advanced technology [4]. Its primary components include extracts of Hyperici perforati Herba and Acanthopanacis Senticosi Radix et Rhizoma Seu Caulis [5]. Numerous studies have reported that SJG exerts significant depressant effects in the clinic with fewer/less severe side effects than Western medicines [5]. However, the antidepressant mechanism of SJG is still unclear. Accordingly, the aim of this study was to systematically investigate the antidepressant effects of SJG and explore its mechanism of action. The results could provide more scientific support for its use in treating clinical depression.

\section{EXPERIMENTAL}

\section{Animals}

Male ICR mice (mean [ \pm SD] weight, $20 \pm 2 \mathrm{~g}$ ) were obtained from the Shanghai Laboratory Animal Center (Shanghai, China). The animals were maintained in a temperature and light controlled environment with ad libitum access to chow and water. The animal protocol adhered to the principles of the Declaration of Helsinki promulgated in 1964 as amended in 1996 [6], and was approved by the animal experiment management department of Affiliated Hangzhou First People's Hospital (Zhejiang, China; no. HZ2018-065).

\section{Chemicals and reagents}

Shu-Gan-Jie-Yu granule (SJG) was product of Beijing Tongrentang (Beijing, China). Imipramine was obtained from Sigma (Sigma-Aldrich Co., St Louis, MO, USA). Commercially available kits used to determine DA, NE, and5-HT were products of Nanjing Jiancheng Bioengineering Institute (Nanjing, Jiangsu, China). Primary antibody for BDNF and $\beta$-actin were purchased from Abcam (Cambridge, United Kingdom).

\section{Forced swimming test (FST)}

The FST experiment was carried out based on a method previously described in the literature [7]. The animals were grouped as follows: control (saline); positive (imipramine, $15 \mathrm{mg} / \mathrm{kg}$,); and SJG-treated groups (200, 400, and $800 \mathrm{mg} / \mathrm{kg}$ ). Imipramine (IMP) was treated by intraperitoneal injection (i.p.) at $30 \mathrm{~min}$ before the experiment. SJG was administered orally at $1 \mathrm{~h}$ before the FST. The mice were forced to swim for $6 \mathrm{~min}$ in a glass jar $(14 \times 14 \times 25 \mathrm{~cm})$ with $20 \mathrm{~cm}$-deep water (mean temperature $25 \pm 2^{\circ} \mathrm{C}$ ). In the last 4 min of the test, the duration time of immobility exhibited by the mice was recorded.

\section{Tail suspension test (TST)}

The TST experiment was also carried out as previously reported [8]. Fifty male mice were grouped as follows: control (saline); positive (IMP); and SJG -treated groups (200, 400 and $800 \mathrm{mg} / \mathrm{kg}$ ). Before $30 \mathrm{~min}$ of the TST experiment, mice in the positive group were treated with IMP (15 mg/kg, i.p.), and SJG was orally administered $1 \mathrm{~h}$ before the TST. Mouse was hung by the tail in a clear black acrylic box $(30 \times 30 \times 45 \mathrm{~cm})$, respectively. Immobility duration was recorded over a test period of 6 $\min$.

\section{Spontaneous behavior in the open-field test (OFT)}

The OFT experiment was carried out as reported in a previous literature [1]. Transparent black acrylic box $(41 \times 41 \times 41 \mathrm{~cm})$ was used and monitored by a video-based camera system (Etho-vision, Noldus, Wageningen, The Netherlands). Fifty male mice were grouped as follows: control (saline); positive (IMP); SJG treated groups (200, 400 and $800 \mathrm{mg} / \mathrm{kg})$. Before $30 \mathrm{~min}$ of the OFT experiment, mice in the positive group were treated with IMP $(15 \mathrm{mg} / \mathrm{kg}$, i.p.). The SJG (200, 400 and $800 \mathrm{mg} / \mathrm{kg}$ ) were orally administered $1 \mathrm{~h}$ before assessing spontaneous behavior in the OFT. To evaluate horizontal locomotor activity of the mice in different groups, mouse was placed in the center of device for $1 \mathrm{~h}$ and recorded by video for $5 \mathrm{~min}$. The frequency of rearing and total ambulatory distance was used to evaluate the horizontal loco-motor activity of mice.

\section{Determination of neurotransmitters in the depressive mice brain}

Depressive mice were identified as described in the TST. These mice were decapitated and the entire brain was removed. The levels of neurotransmitters (DA, NE, and 5-HT) in brain tissue were determined using commercially available kits according to manufacturers' instructions.

Trop J Pharm Res, September 2020; 19(9): 1928 


\section{Western blot analysis}

Collected brain tissues were homogenized to extract total proteins. Subsequently, samples (40 $\mu \mathrm{g}$ of total protein in each sample) were separated on SDS-PAGE. Proteins were transferred to polyvinylidene fluoride membranes, and then probed using various primary BDNF antibody, followed by the appropriate secondary antibody. The protein bands were stained with chemiluminescence reagent. Protein content was normalized to a $\beta$ actin control.

\section{Statistical analysis}

Data are expressed as mean \pm S.D. Statistical analyses were carried out using the two-tailed Student's $t$ test (ANOVA) using SPSS 16.0 software (SPSS Inc., USA). $p<0.05$ was regarded as a significance level.

\section{RESULTS}

\section{Effect of SJG on depressive mice in FST}

As shown in Figure 1, immobility time of mice treated with imipramine was obviously shorter ( $p$ $<0.01)$ than that of the mice in the control group. Interestingly, SJG treatments (200, 400 and 800 $\mathrm{mg} / \mathrm{kg}$ ) also markedly shortened the immobility duration time of depressive mice $(p<0.05, p<$ $0.05, p<0.01$, respectively).

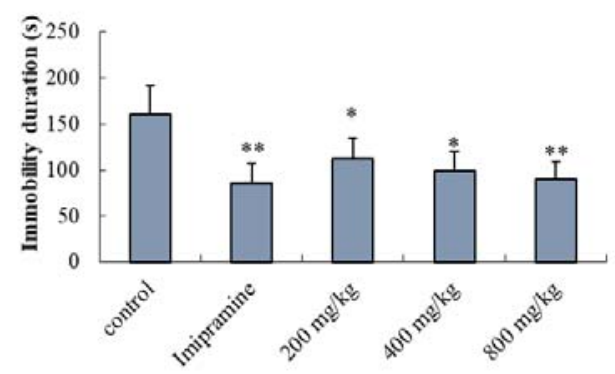

Figure 1: FST results for SJG. Each column represented the mean $\pm S D$. $(n=10)$. Asterisks indicated significant difference from control; ${ }^{*} p<0.05$, ${ }^{* *} p<0.01$

\section{Effect of SJG on mice with depression in TST}

Results of effects of SJG on the mice with depression in TST experiment are presented in Figure 2. Relative to the control group, IMP (15 $\mathrm{mg} / \mathrm{kg}$ ) treatment markedly reduced the immobility time of depressive mice $(p<0.01)$. The immobility time of mice in SJG-treated groups (400 and $800 \mathrm{mg} / \mathrm{kg}$ ) was apparently shorter $(p<0.05)$ than that of the normal control mice.

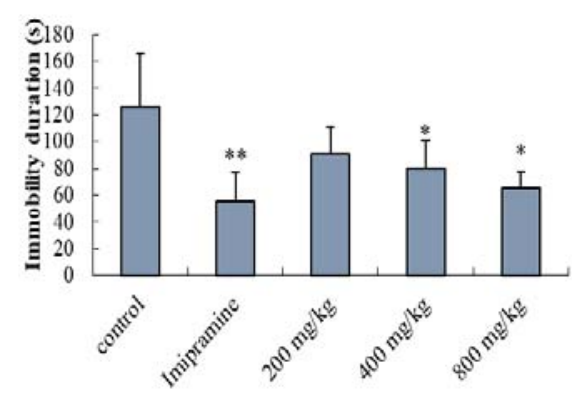

Figure 2: TST results for the SJG. Each column represents the mean $\pm S D$. $(n=10)$ Asterisks indicated significant difference from control; ${ }^{*} p<0.05$, ${ }^{* *} p<0.01$

\section{Effect of SJG on mice with depression in OFT}

As shown in Figure 3, compared with mice in the control group, after SJG (800 mg/kg) treatment, the mobility of depressive mice was markedly increased $(p<0.05)$. In addition, IMP treatment also significantly affected the mobility of depressive mice when compared with the normal control mice $(p<0.05)$.

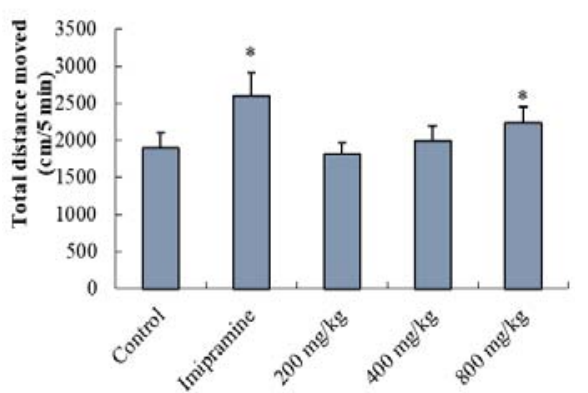

Figure 3: OFT results for SJG. Each column represented the mean $\pm S D$. $(n=10)$. Asterisks indicate significant difference from control; ${ }^{*} p<0.05$

\section{Effect of SJG on neurotransmitters in depressive mouse brain}

Effect of SJG on neurotransmitters in depressive mouse brain were shown in Figure 4. Compared with the control group, it can be seen that different doses of SJG remarkably increased the 5 -HT level in the brains of depressive mice at 200,400 , and $800 \mathrm{mg} / \mathrm{kg}$. The DA and NE levels in mice in the SJG-treated group were also significantly increased $(p<0.05)$ when compared to the normal control mice. 


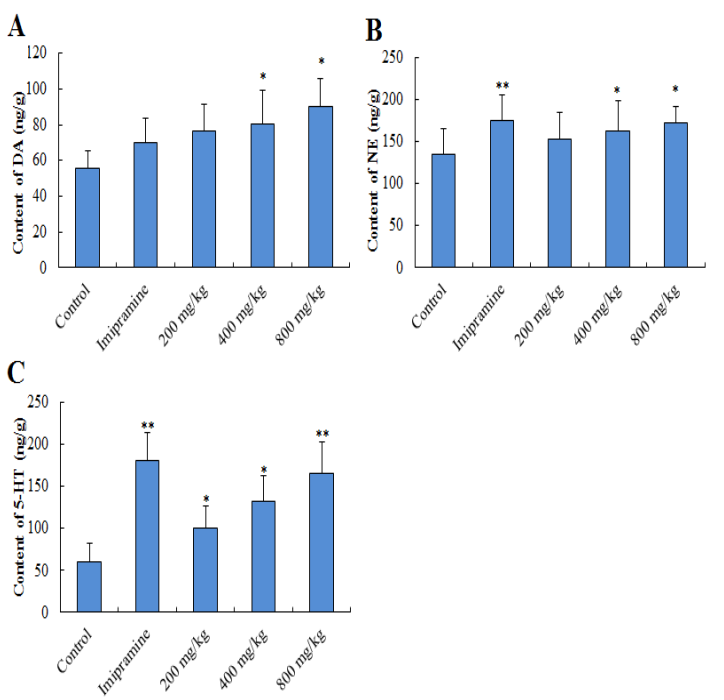

Figure 4: DA, NE, and 5-HT levels in depressive mouse brain. Each column represented the mean \pm SD $(n=10)$. Asterisks indicated significant difference from control; ${ }^{*} p<0.05,{ }^{* *} p<0.01$

Effect of SJG on BDNF expression in depressive mouse brain

As shown in Figure 5, different doses of SJG (200, 400 and $800 \mathrm{mg} / \mathrm{kg}$ ) markedly enhanced the expression of BDNF in the brains of depressive mice $(p<0.05, p<0.05$, and $p<$ 0.05 , respectively), relative to the normal control mice.

BDNF

$\beta$-actin

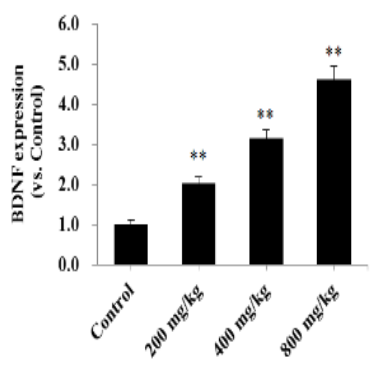

Figure 4: Expressions of BDNF in the depressive mice brain. Each column represented the mean \pm SD. $(n=10)$. Asterisks indicate significant difference from control. ${ }^{*} p<0.05,{ }^{* *} p<0.01$

\section{DISCUSSION}

Behavioral despair models often include forced swim and tail suspension, both of which provide an unavoidable and oppressive environment. The duration of immobility of animals in the experiment after effort reflects a state known as "behavioral despair" $[10,11]$. The immobility time of "behavioral despair" can reflect the degree of depression in animals, while antidepressants reduce immobility time; in other words, the lower the immobility time, the stronger the antidepressant effect.

These two models are fast, simple and sensitive to most antidepressants. Thus, they have been widely used in the preliminary screening of various antidepressants. In addition, the OFT can effectively reflect spontaneous behavior, activity, and emotional state of the animals, and its activity intensity can also indicate excitation or inhibition of the central nervous system (CNS) [12]. It is known that increases in animal motor activity elicited by a drug(s) reflects excitation of the CNS.

The behavior despair models were employed in in this study, and the results showed that SJG exhibited anti-depressive activity, which reflect its powerful anti-depressive effects. Moreover, the results of OFT demonstrated that SJG treatment clearly altered the locomotor activity of depressive mice.

The decrease of some brain neurotransmitters (DA, NE and 5-HT, etc.) can lead to depression. Therefore, upregulation of these neurotransmitters in the brain is of great significance for the improvement of depression [13]. The present results indicated that the levels of brain neurotransmitters (DA, NE, and 5-HT) were increased after SJG treatment. In addition, as a neurotrophic factor, BDNF is indispensable for the function of neurons, such as growth, survival and differentiation [14]. It is also involved in improving the function of learning and memory, and has antidepressant effect [1]. The present study found SJG exerted significantly antidepressant effect by increasing the expression of BDNF in the brains of depressive mice.

\section{CONCLUSION}

The findings of this study demonstrate that SJG possesses antidepressant effects that modified the CNS, leading to reduced immobility, and altered motor and exploratory activity. Thus, SJG possesses antidepressant activity, and can be potentially developed as an antidepressant medication.

\section{DECLARATIONS}

\section{Acknowledgement}

This work was supported by The Science and Technology Planning Project of Zhejiang Traditional Chinese Medicine (no. 2019ZB098). 


\section{Conflict of interest}

The authors declare that no conflict of interest is associated with this work.

\section{Contribution of authors}

The authors declare that this work was done by the authors named in this article and all liabilities pertaining to claims relating to the content of this article will be borne by them. All authors approved the manuscript for publication. For preparation of the paper, Min Wu conceived the study; Li-shu Gao, Min Wu, Yue Gao, En-ping $\mathrm{Xu}$, Jian Xie collected and analyzed the data; Lishu Gao and Min Wu wrote the manuscript.

\section{Open Access}

This is an Open Access article that uses a funding model which does not charge readers or their institutions for access and distributed under the terms of the Creative Commons Attribution License (http://creativecommons.org/licenses/by/ 4.0) and the Budapest Open Access Initiative (http://www.budapestopenaccessinitiative.org/rea d), which permit unrestricted use, distribution, and reproduction in any medium, provided the original work is properly credited.

\section{REFERENCES}

1. Han $P$, Han $T$, Peng W, Wang XR. Antidepressant-like effects of essential oil and asarone, a major essential oil component from the rhizome of Acorus tatarinowii. Pharm Biol 2013, 51: 589-594.

2. Wang HY, Guo DM, Tang Z, Chen JX. Antidepressant effect and mechanism of Shu-gan-Jie-yu granule. Chin Tradit Patent Med 2018, 40(1): 187-190.

3. Wang Y, Han T, Zhu Y, Zheng CJ, Ming QL, Rahman K, Qin LP: Antidepressant properties of bioactive fractions from the extract of Crocus sativus L. J Nat Med 2010; 64: $24-30$.
4. Psychiatric Branch of Chinese Medical Association. The Chinese Classification and Diagnosis of Mental Diseases -3rd edition; Jinan: Shandong Science And Technology Press, 2001; $p$ 87-88.

5. L Y, Li WT, Qin SC, Zhang JY, Jia YJ, Xu Y. Clinical study of Shugan Jieyu capsules in treating depression. J Shanxi Coll Tradit Chinese Med 2018; 19(5): 74-77.

6. World Medical Organization. Declaration of Helsinki. British Medical Journal (7 December) 1996; 313(7070): 1448-1449.

7. Herrera-Ruiz $M$, Zamilpa A, González-Cortazar $M$, Reyes-Chilpa R, León E, García MP, Tortoriello J, Huerta-Reyes $M$. Antidepressant effect and pharmacological evaluation of standardized extract of flavonoids from Byrsonima crassifolia. Phytomed 2011; 18: $1255-1261$.

8. Lu MZ, Zhang ZQ, Yin J, Chen WS, Hou ZH, Li TZ. Study on the effect and mechanisms of timosaponin B-Il on antidepressant. J Pharmaceut Pract 2010; 18(4): 283287.

9. An L, Zhang YZ, Yu NJ, Liu XM, Zhao N, Yuan L, Li YF. Role for serotonin in the antidepressant-like effect of a flavonoid extract of Xiaobuxin-Tang. Pharmacol Biochem Beha 2008; 89: 572-580.

10. Renard CE, Dailly E, David DJ, Hascoet M, Bourin M. Monoamine metabolism changes following the mouse forced swimming test but not the tail suspension test. Fundamental\& Clinical Pharmacology 2003; 17(4): 449455.

11. Borsini F, Voltera G, Meli A. Does the behavioral despair test measure. Physiol Behavior 2003; 38(3): 385-386.

12. Prut L, Belzung $C$. The open field as a paradigm to measure the effects of drugs on anxiety-like behaviors: a review. Eur J Pharmacol 2003, 463(1-3): 3-33.

13. Zhang $Y J$, Huang $W$, Huang $X$, Wang $Y$, Wang $Z$, Wang $C$, Zhou BW, Sheng CX, Wang B, Zhang SF, et al. Fructus Aurantii induced antidepressant effect via its monoaminergic mechanism and prokinetic action in rat. Phytomed 2012; 19: 1101-1107.

14. Lee S, Kim DH, Lee CH, Jung JW, Seo YT, Jang YP, Ryu JH. Antidepressant-like activity of the aqueous extract of Allium macrostemon in mice. $\mathrm{J}$ Ethnopharmacol 2010; 131: 386-395. 